\title{
Suspended Particulate Matter Pollution in Jabalpur: A Case Study
}

\section{Srivastava RK* and Rajasree Sarkar}

Environmental Research Laboratory, PG Department of Environmental Science, Government Model Science College, Jabalpur, Madhya Pradesh, India

\begin{abstract}
In this study, the environmental effects of suspended particulate matter include accelerated corrosion of metals, as well as damage to paints, sculptures, and soil-exposed surfaces on man-made structures. It can be concluded that among the residential areas. In Jabalpur city at Ranji Basti is showing the high SPM quantity and Chotiline phatak is the high traffic zone with the highest concentration of SPM. It has been found that pollution level caused by the SPM is comparatively high in Badafuhara, In all over the year, Adhartal industrial sector is showing the maximum pursuance of SPM in the city among the three industrial sectors, This indicates that the pollution level is less in the industrial zones of the city as compared with the other major cities/metros, as the industrial zone is not so very well established.
\end{abstract}

Keywords: Air pollution; Air quality; Suspended particulate matter

\section{Introduction}

Burning fossil fuels in the production of electricity is a source of pollution contributing to ozone formation. Air Pollution is one of the most challenging problems facing the international community; it is widespread and growing in importance and has clear and known impacts on health and the environment. The human need for transport, manufactured goods and services brings with it impacts on the atmospheric environment at scales from the local to the global. Whilst there are good examples of regulatory successes in minimizing such impacts, the rate of development of the global economy bring new pressures and the willingness of governments to regulate air pollution is often balanced by concerns over the economic impact of regulation. Science is the key to identifying the nature and scale of air pollution impacts and is essential in the formulation of policy relevant information for regulatory decision-making. Continuous improvements in our knowledge of the fundamental science of air pollution and its application are necessary if we are to properly predict, assess and mitigate the air pollution implications of changes to the interlinked local, regional, national and international economic systems.

Air pollution began to increase in the beginning of the $20^{\text {th }}$ century with the development of transportation systems and large scale use of petrol and diesel. The severe air quality problems due to the formation of petrochemical smog from the combustion residues of diesel and petrol engines were felt for the first time in Los Angles. Pollution due to the auto exhaust remains a serious environmental issue in many developed and developing countries, including India. Particulates are small pieces of solid material like smoke particles from fibers, bits of asbestos, dust particles and ash from industries dispersed into the atmosphere. The effect of particulate range from soot to the carcinogenic effects of asbestos, dust particles and ash from industrial plants that are dispersed into the atmosphere. Repeated exposer to particulates can cause them to accumulate in the lungs and interfere with the ability of the lungs to exchange gases. The study on air pollution specially suspended particulate matter has not been done in Jabalpur. So far, the data generated in the study will be helpful for proper planning and management in this area as well as other part of the country.

This paper is to summarize the impacts of suspended particulate pollution in a city like Jabalpur which is also known as marble city.

\section{Materials Required}

The study is mainly highlighting upon the four selected zones or areas of the city they are High traffic zones - Chotiline phatak (HT1), Damohnaka (HT2), Wright town motor stand (HT3). Commercial zones -Gorakhpur market (CM1), Bada Fuhara (CM2), Ranjhi market (CM3). Residential zones- Ranjhi basti (RS1), Samiksha town, Kanchghar station road (RS2), Awadhpuri, Gwarighat (RS3). Industrial Zones - Adhartal industrial area (ID1), Richhai industrial area (ID2), Shaw Wallace Bhedaghat (ID3). In each category three sampling points are selected. The city map of Jabalpur showing all the selected locations is shown in Figure 1.

Period of sampling for the particulate monitoring is $24 \mathrm{hrs}$ respectively. In this study the sampling is done on monthly basis from (October 2005 to September 2006).

The measurement of SPM was done as per standard procedure laid down by manufacturer of high volume air sampler, and IS: 5182- part IV 1973.

The mass of particulates collected is measured gravimetrically, using balance capable of reliable measurement to the nearest microgram.

\section{Calculations}

Formula used areas follows

$$
\begin{aligned}
& \text { 1. } \mathrm{V}=\mathrm{Q} \times \mathrm{T} \\
& \text { 2. } \mathrm{Q}=\mathrm{Q}_{1}+\mathrm{Q}_{2} / 2 \\
& \text { 3. } \mathrm{W}_{\mathrm{RPM}}=\mathrm{F}_{2}-\mathrm{F}_{1} \\
& \text { 4. } \mathrm{C}_{\mathrm{RPM}}=\mathrm{W}_{\mathrm{RPM}} / \mathrm{V} \\
& \text { 5. } \mathrm{W}_{\mathrm{NRPM}}=C_{2}-C_{1} \\
& \text { 6. } \mathrm{C}_{\mathrm{NRPM}}=\mathrm{W}_{\mathrm{NRPM}} / \mathrm{V}
\end{aligned}
$$

*Corresponding authors: Srivastava RK, Environmental Research Laboratory, PG Department of Environmental Science, Government Model Science College, Jabalpur, Madhya Pradesh, India, Tel: +919926659131; E-mail: kalpanasagar.sagar2@gmail.com

Received July 22, 2016; Accepted August 16, 2016; Published August 22, 2016

Citation: Srivastava RK, Sarkar R (2016) Suspended Particulate Matter Pollution in Jabalpur: A Case Study. J Environ Anal Toxicol 6: 396. doi: 10.4172/21610525.1000396

Copyright: ( $\odot 2016$ Srivastava RK, et al. This is an open-access article distributed under the terms of the Creative Commons Attribution License, which permits unrestricted use, distribution, and reproduction in any medium, provided the original author and source are credited. 


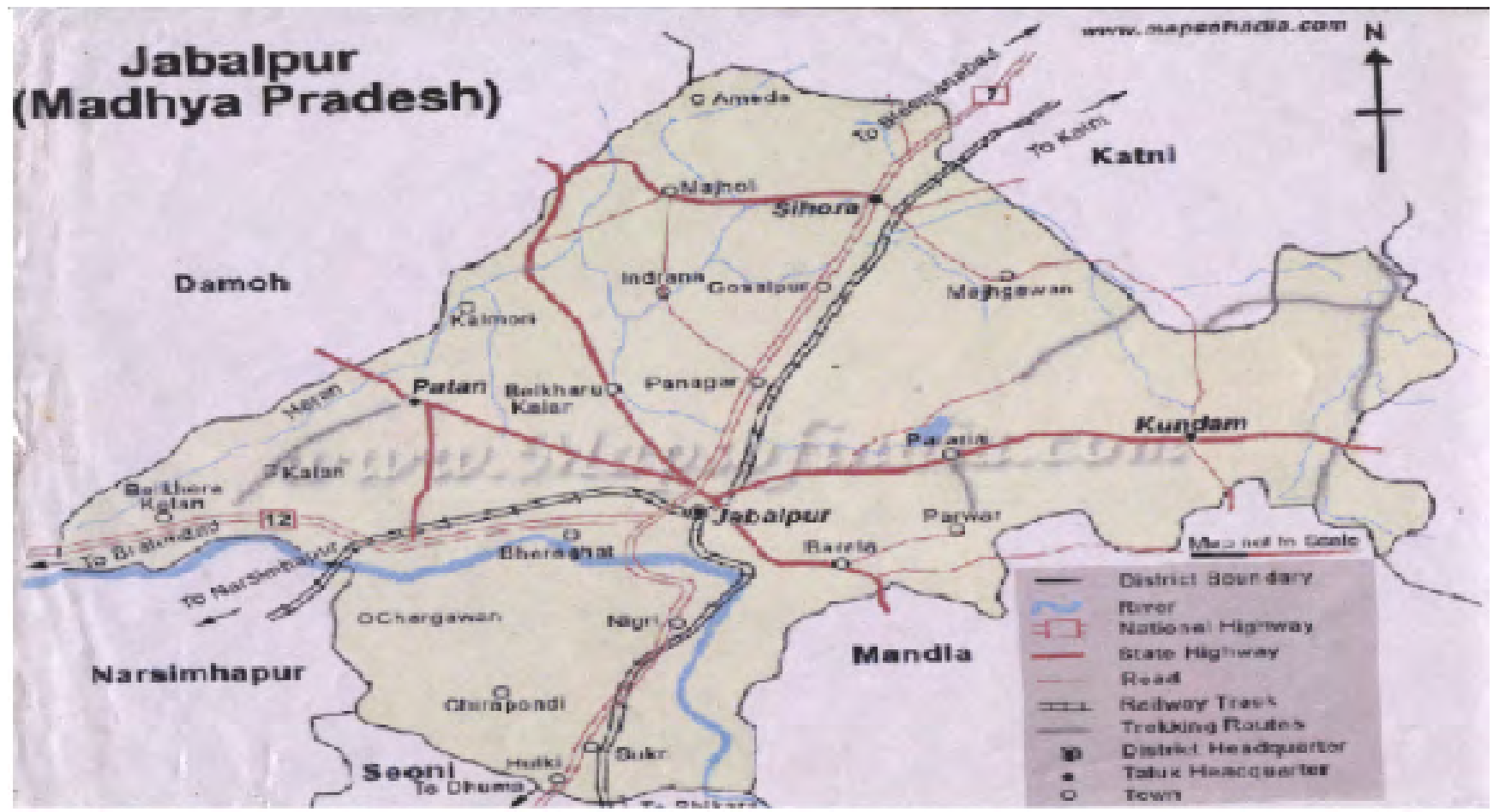

Figure 1: City map of Jabalpur showing all the selected locations.

\section{7. $\mathrm{C}_{\mathrm{SPM}}=\mathrm{RPM}+\mathrm{NRPM}$}

Where,

$\mathrm{T}=$ Time of sampling, $\mathrm{V}=$ Volume of air sampled, $\mathrm{Q}=$ Average flow, $\mathrm{Q}_{1}=$ Initial flow, $\mathrm{Q}_{2}=$ Final flow, $\mathrm{W}_{\mathrm{RPM}}=$ Weight of Respirable particulate matter, $F_{2}=$ Final weight of filter paper, $F_{1}=$ Initial weight of filter paper, $\mathrm{C}_{\mathrm{RPM}}=$ Concentration of RPM, $\mathrm{W}_{\mathrm{NRPM}}=$ Weight of Non-Respirable particulate matter, $C_{2}=$ Final cup weight, $C_{1}=$ Initial weight of cup, $\mathrm{C}_{\mathrm{NRPM}}=$ Concentration of NRPM, $\mathrm{C}_{\mathrm{SPM}}=$ Concentration of suspended particulate matter.

Precaution- both blank and samples should be conditioned at $20^{\circ} \mathrm{C}$ to $25^{\circ} \mathrm{C}$, and relative humidity below $50 \%$ for at least 16 hours prior to weighing.

\section{Results and Discussion}

The particulate matter has been measured for a complete year i.e., from October' 05 to September'06 for the sampling of SPM, the particulate matters in the city of marble rocks. After studying the impact of the particulate pollutant in the atmosphere of the residential sector of the city, it has been noted that the highest concentration is coming in January'06 in RanjhiBasti, which is $89.2 \mu \mathrm{g} / \mathrm{m}^{3}$. RanjhiBasti is also counted as having the most number of maximum SPM concentrations among the residential areas.

But the summer months like March and May is contributing the maximum concentration of SPM viz $82.4 \mu \mathrm{g} / \mathrm{m}^{3}$ and $89.0 \mu \mathrm{g} / \mathrm{m}^{3}$ in Samiksha town and Awadhpuri. The high value during the summer may be due to the extreme temperature [1]. This change is may be due to the meteorological changes and / or may be due to the civil construction in Samiksha town. This result shows that the values of the pollutants are well within limits of $200 \mu \mathrm{g} / \mathrm{m}^{3}$ set by the CPCB.
It is clear that RanjhiBasti is quiet polluted with the suspended particulate pollutant, On considering the high traffic zone, the pollutant namely SPM is showing the highest concentration of $211.2 \mu \mathrm{g} / \mathrm{m}^{3}$ in Chotilinephatak and in the month of May and in the month of April Chotilinephatak is showing the concentration $201.4 \mu \mathrm{g} / \mathrm{m}^{3}$. This can be discussed as the vehicular exhaust account for more than $50 \%$ of the total pollution from all the sources put together in all the major cities. This is supported by Ref. [2]. These two values are exceeding the limit of $200 \mu \mathrm{g} / \mathrm{m}^{3}$ set by CPCB. The minimum concentration has been measured in the month of august $\left(71.4 \mu \mathrm{g} / \mathrm{m}^{3}\right)$ for Wright town motor stand. This predicts that rain water fixes the particles in the land i.e., the dust dissolves in the rainwater. Seasonal average of SPM concentration was lowest in the monsoons.

The individual study detects that Damohnaka is commonly showing the highest concentration of the pollutant. From the result it can be concluded that SPM is the main pollutant within the city- the reason being the growing number of automobiles and poorly and congested roads. Poorly maintained autorickshaws are also the main cause of pollutants. This can be reduced by properly maintained and eco-friendly mass transportation system [3].

The result for the commercial sector is being discussed here for the pollutant SPM. When we look into the pollutant SPM on an individual basis, it has been found that SPM is getting hike in Badafuhara commercial area, the value is $137.8 \mu \mathrm{g} / \mathrm{m}^{3}$ in the month of April. This site is also having the maximum number of the highest average concentration, may be due to canyon street formation. Most of the pollution emitted from vehicles comes from exhaust, causing significant concentration of pollutants around traffic [4]. As the traffic density is fair here but it is slow, thus the particles coagulate. The road of the market is surrounded by the tall buildings. This also obstructs the dispersion of the pollutant 
Citation: Srivastava RK, Sarkar R (2016) Suspended Particulate Matter Pollution in Jabalpur: A Case Study. J Environ Anal Toxicol 6: 396. doi: 10.4172/2161-0525.1000396

Page 3 of 7

particles, thus, causing more concentration of particles. This work is supported by Ref. [5] and Ref. [6]. The minimum average concentration for the particulate pollutant SPM is recorded in the site namely Ranjhi market of $58.6 \mu \mathrm{g} / \mathrm{m}^{3}$ in the month of September.

In all over the year, Adhartal industrial sector is showing the maximum pursuance of SPM in the city among the three industrial sectors, and the highest concentration is in the month of April, which is of $181.9 \mu \mathrm{g} / \mathrm{m}^{3}$. This result shows that Adhartal industrial zone is the most polluted zone among the three industrial sectors. The readings are well in limit given by CРCB. This indicates that the pollution level is very less in the industrial zones of the city. As the industrial zone is not so very well established. The graphical representation of the result is given below (Figures 2-13).

\section{Conclusion}

From the study it can be concluded that among the residential areas of the city Ranji Basti is showing the high SPM quantity and Chotiline phatak is the high traffic zone with the highest concentration of SPM. It has been found that pollution level caused by the SPM is comparatively high in Badafuhara, In all over the year, Adhartal industrial sector is showing the maximum pursuance of SPM in the city among the three industrial sectors, This indicates that the pollution level is less in the industrial zones of the city as compared with the other major cities/ metros, as the industrial zone is not so very well established. The road of the market is surrounded by the tall buildings. This also obstructs the dispersion of the pollutant particles, thus, causing more concentration of particles. The elemental composition of particulate aerosol at the city is clearly affected by anthropogenic activities especially transport and industrial activities and the high trace composition in this area may affect the ecosystem and public health of the region. So by this study it can be concluded that ambient air monitoring has become an important topic for research. The elemental composition of particulate aerosol at the city is clearly affected by anthropogenic activities especially transport and industrial activities and the high trace composition in this area may affect the ecosystem and public health of the region. Same way, SPM (suspended particulate matter) has become the main pollutant within the city due to increasing numbers of automobiles and poorly and congested roads.

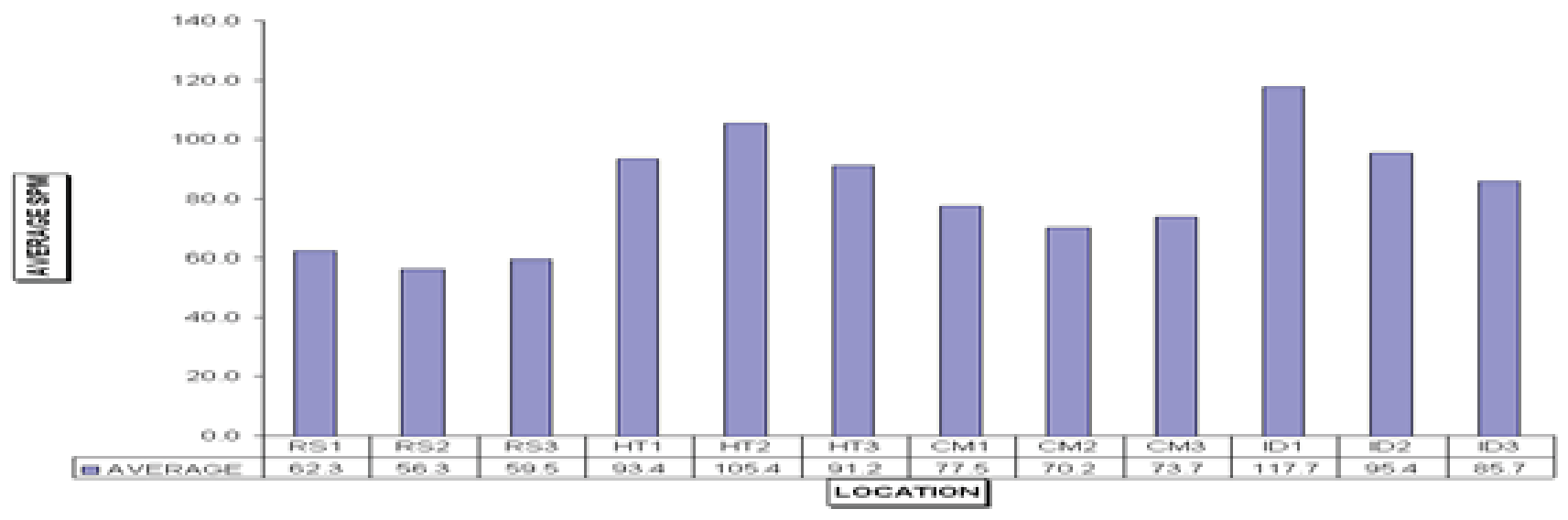

Figure 2: Average SPM at different sampling stations in the month of October 05.

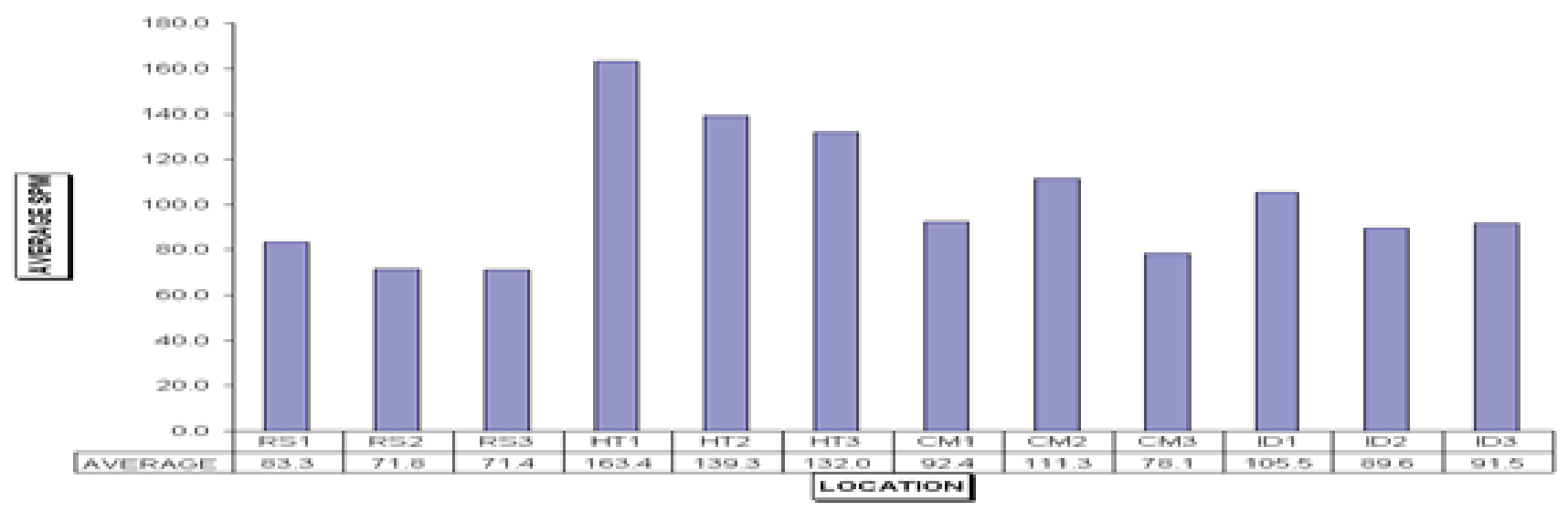

Figure 3: Average SPM at different sampling stations in the month of November 05. 
Citation: Srivastava RK, Sarkar R (2016) Suspended Particulate Matter Pollution in Jabalpur: A Case Study. J Environ Anal Toxicol 6: 396. doi: 10.4172/2161-0525.1000396

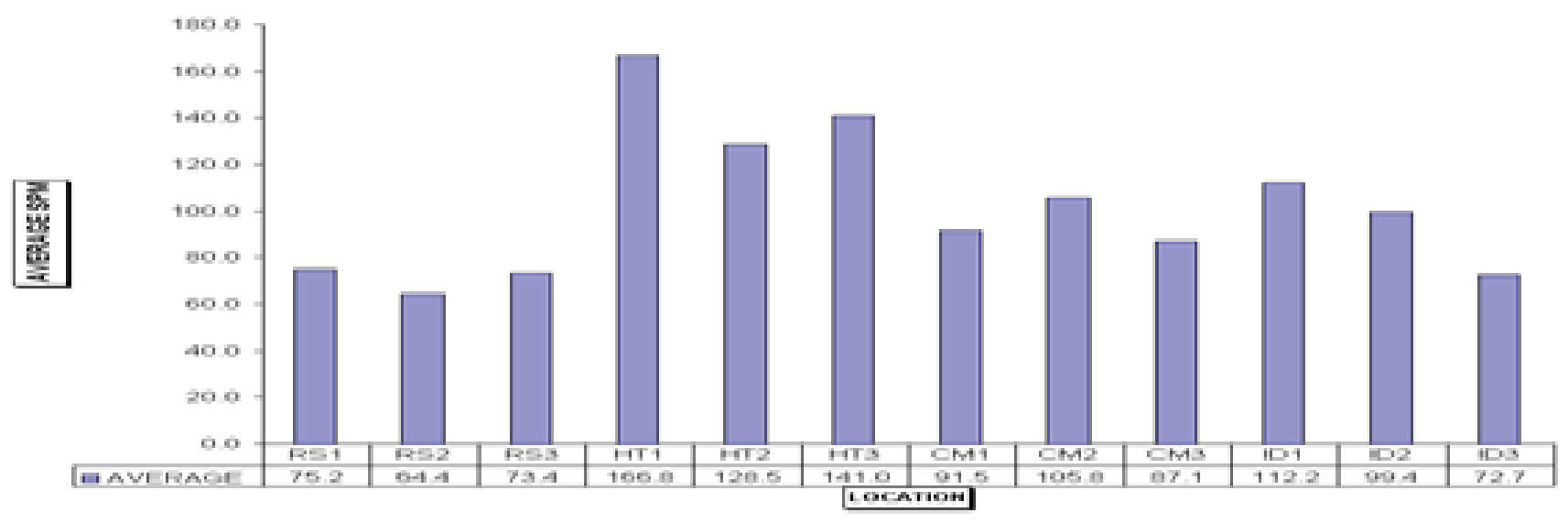

Figure 4: Average SPM at different sampling stations in the month of December 05.

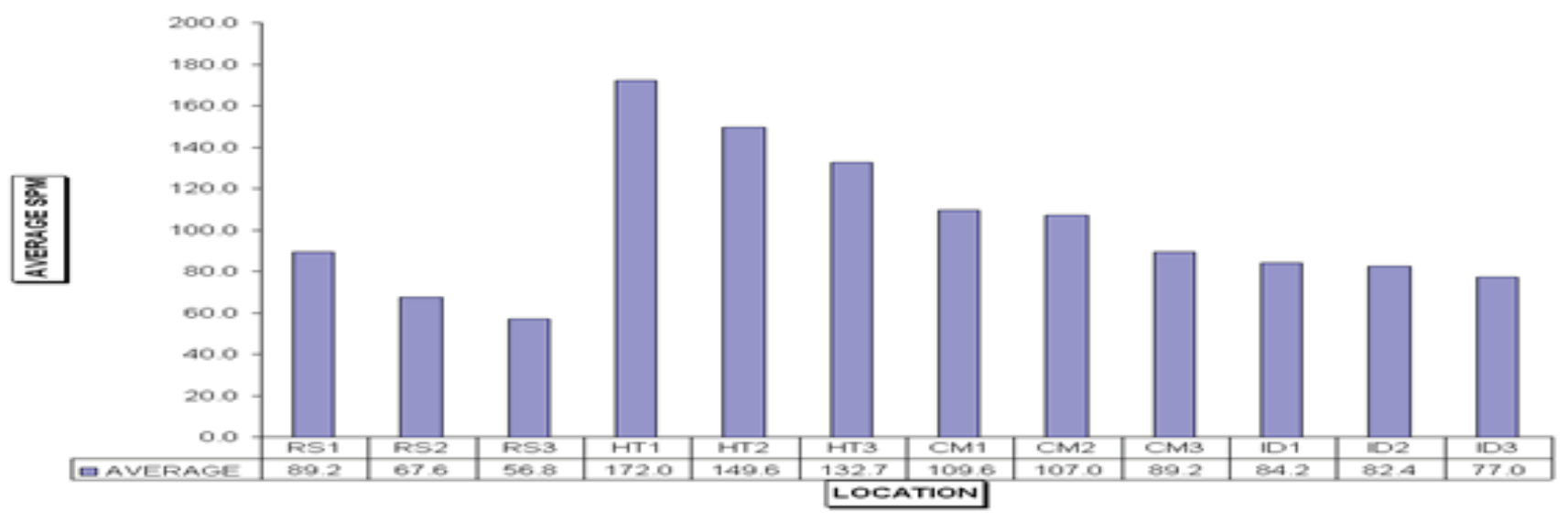

Figure 5: Average SPM at different sampling stations in the month of January 06.

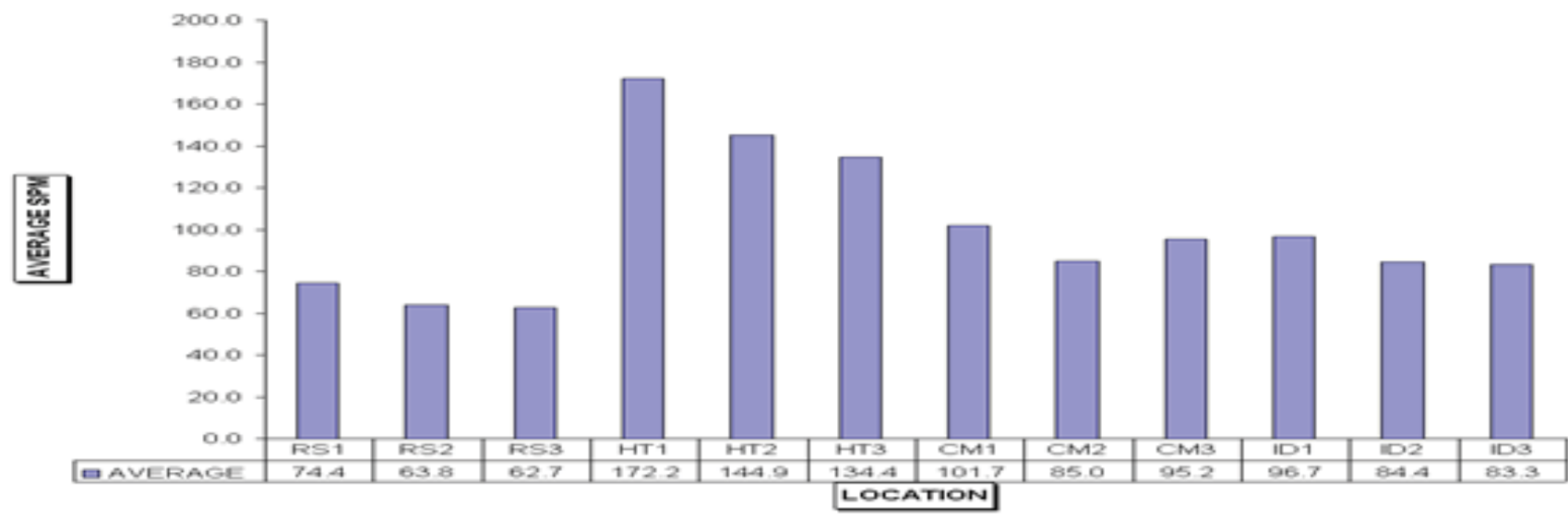

Figure 6: Average SPM at different sampling stations in the month of February 06. 
Citation: Srivastava RK, Sarkar R (2016) Suspended Particulate Matter Pollution in Jabalpur: A Case Study. J Environ Anal Toxicol 6: 396. doi: 10.4172/2161-0525.1000396

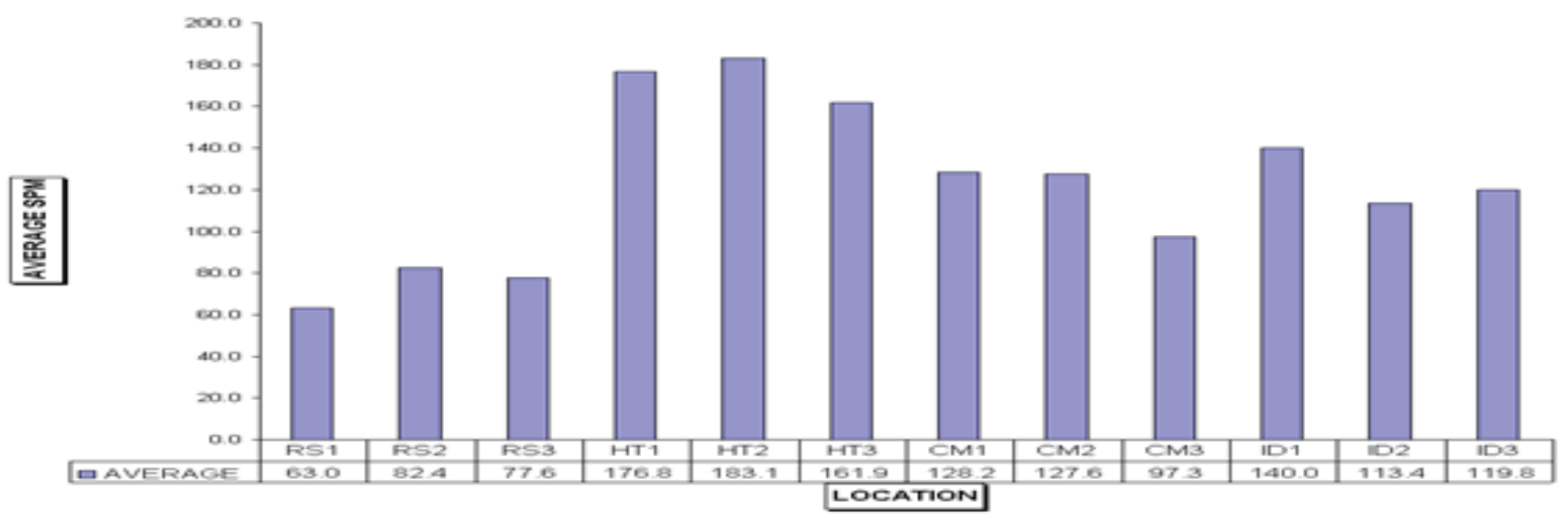

Figure 7: Average SPM at different sampling stations in the month of March 06.

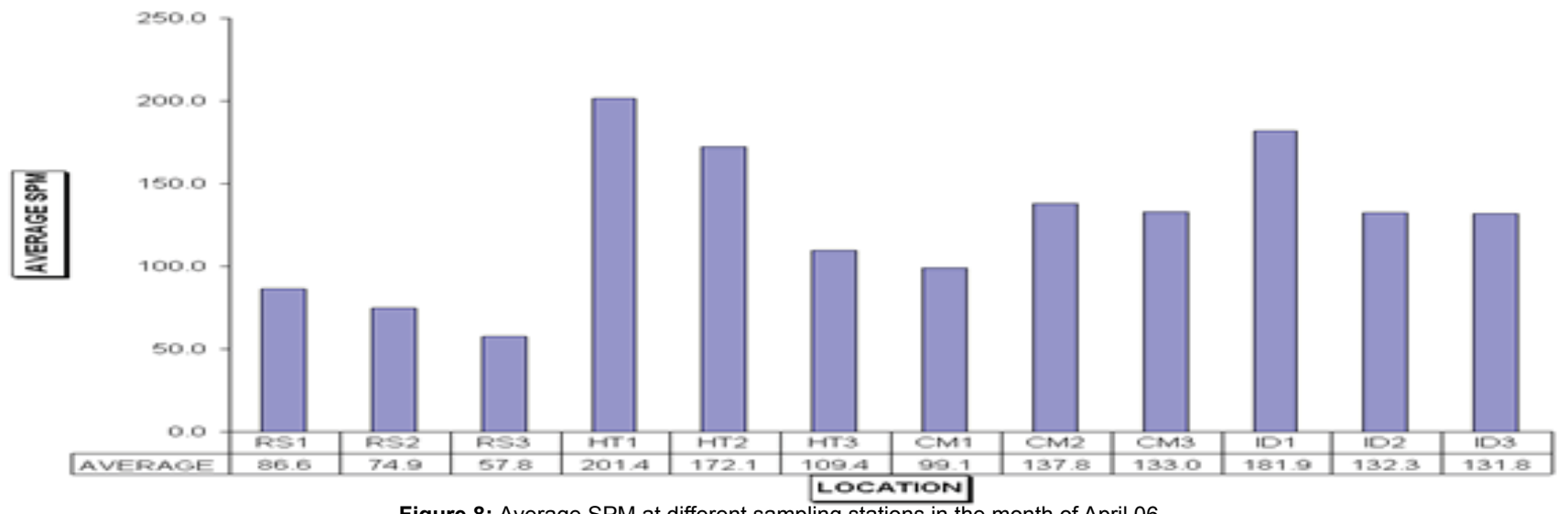

Figure 8: Average SPM at different sampling stations in the month of April 06.

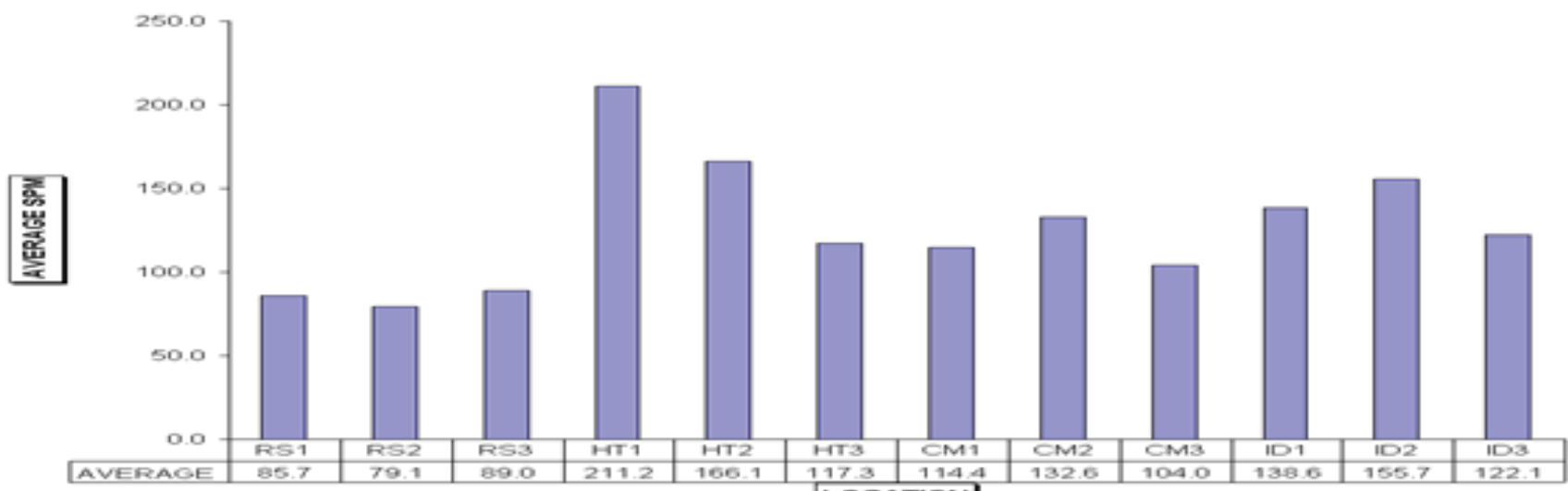

LOCATION

Figure 9: Average SPM at different sampling stations in the month of May 06. 
Citation: Srivastava RK, Sarkar R (2016) Suspended Particulate Matter Pollution in Jabalpur: A Case Study. J Environ Anal Toxicol 6: 396. doi: 10.4172/2161-0525.1000396

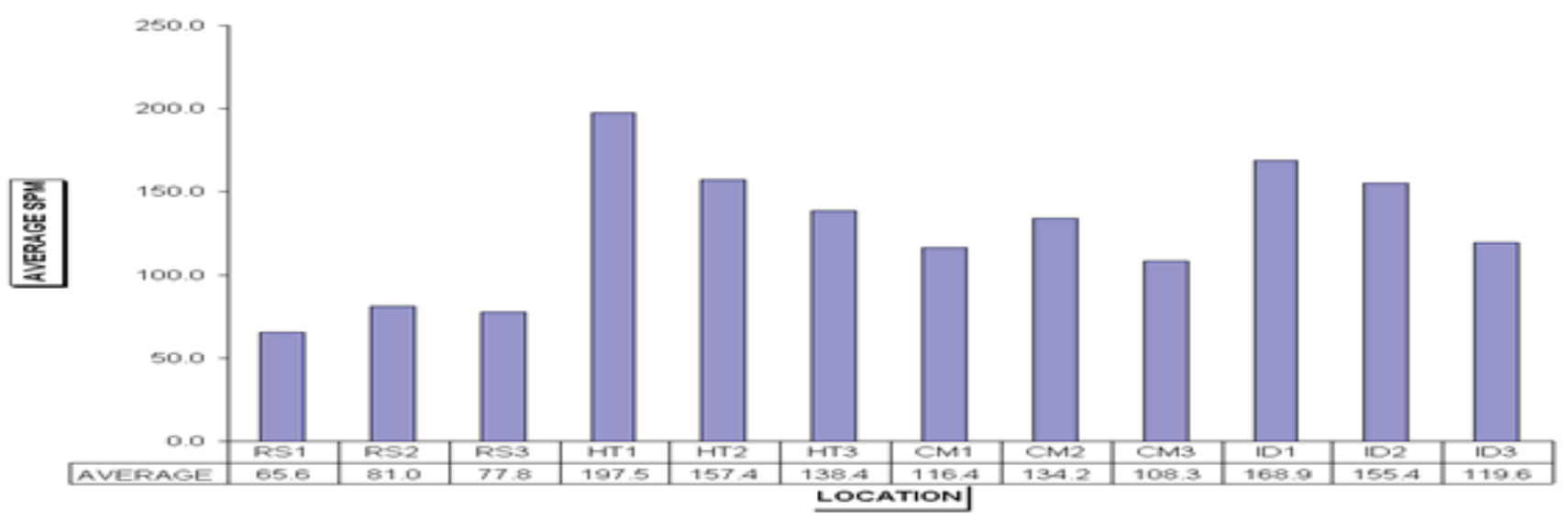

Figure 10: Average SPM at different sampling stations in the month of June 06.

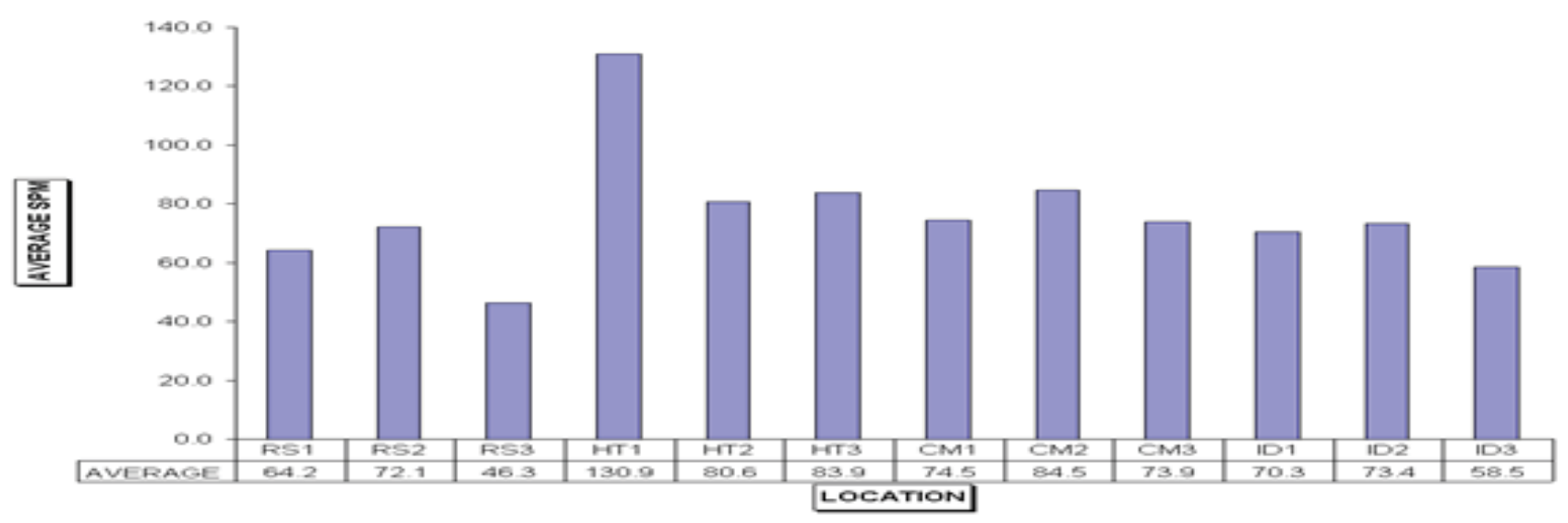

Figure 11: Average SPM at different sampling stations in the month of July 06.

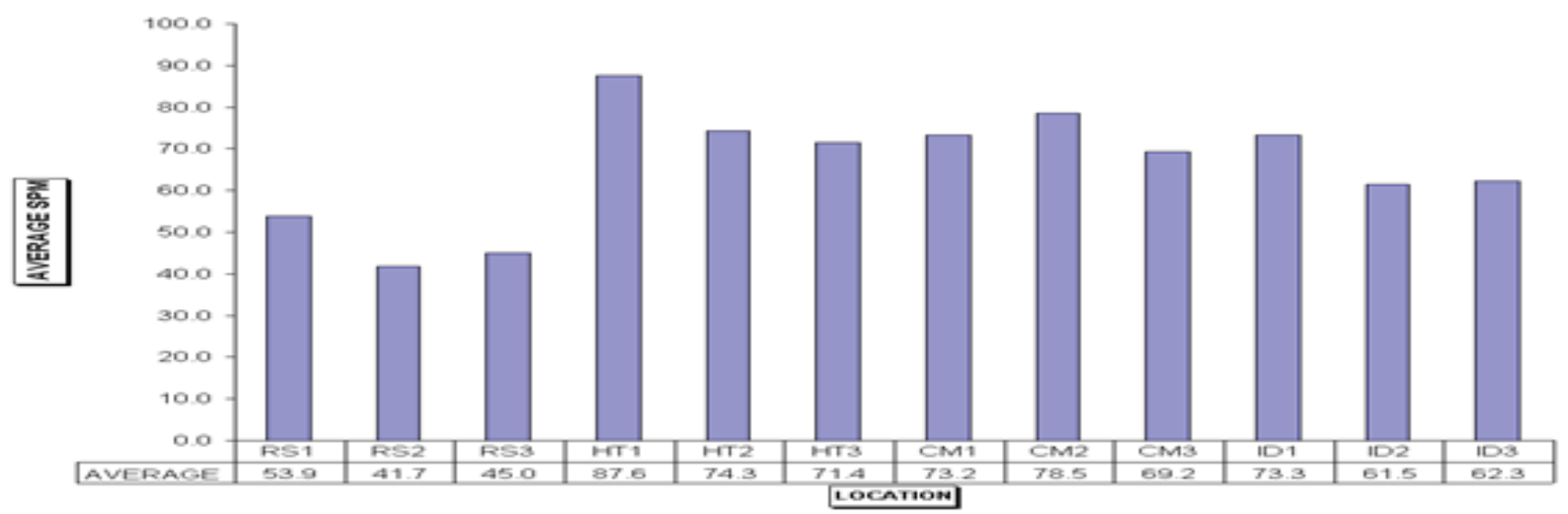

Figure 12: Average SPM at different sampling stations in the month of August 06. 
Citation: Srivastava RK, Sarkar R (2016) Suspended Particulate Matter Pollution in Jabalpur: A Case Study. J Environ Anal Toxicol 6: 396. doi: $10.4172 / 2161-0525.1000396$

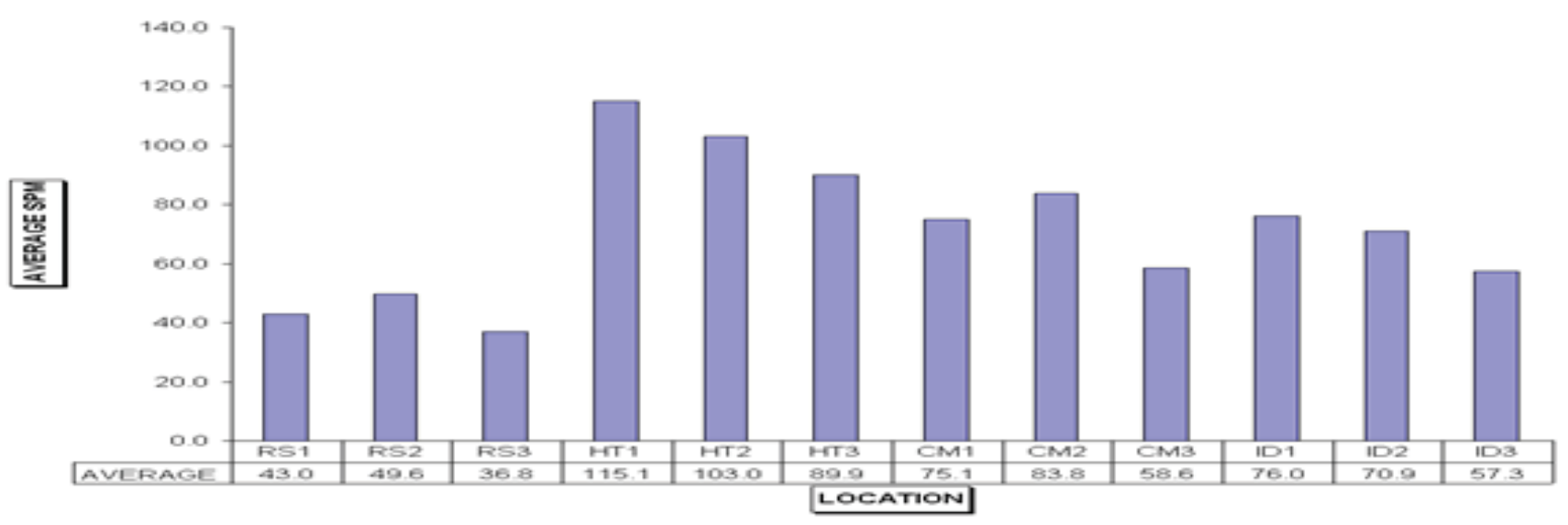

Figure 13: Average SPM at different sampling stations in the month of September 06.

\section{References}

1. Srivastava RK, Ayachi AK, Sen A (2004) Status of Ambient Air Quality of Gelatine Factory at Bhedaghat, Jabalpur. Industrial Pollution and Management, p: 166

2. Mathur HB (1992) Impact of Surface transport on air environment of major metropolitan cities of India. National Program on recent advances in environmental pollution. New Delhi Proceedings, pp: 14-21.

3. Srivastava AK, Singh RS, Sachan AK (2002) Level of air contaminants in Jhansi city. Indian Journal of Environmental Protection 22: 327-328.
4. Clifford MJ, Clarke R, Riffat SB (1997) Local aspects of vehicular pollution Atmos. Env 31: 271-276.

5. Claiborn C, Mitra A, Adams G, Bamesberger L, Allwine G, et al. (1995) Evaluation of PM10 emission rates from paved and unpaved roads using tracer techniques. Atmospheric environment 29: 1075-1089.

6. Monn C, Braendli O, Schaeppi G, Schindler C, Ackermann-Liebrich U, et al (1995) Particulate matter $<10 \mu \mathrm{m}$ (PM 10) and total suspended particulates (TSP) in urban, rural and alpine air in Switzerland. Atmospheric Environment 29: 2565-2573. 